\title{
APPLICATION OF DRIFTING BUOYS IN OCEAN RESEARCH
}

\author{
Haruo Ishii*, Ryoki Saruwatari*, Yoshizo Ueno*, \\ Shigeki Kuramoto* and Hideo Nishida*
}

Received 1981 October 26

\begin{abstract}
Since January 1980, nine drifting buoys tracked by satellites have been deployed to investigate surface current structure in the Kuroshio region. This buoy-tracking experiment is being carried out by the Hydrographic Department of Japan using the ARGOS system. The comparison of buoy positions determined by the satellites with the known position of land shows satisfactory accuracy. The estimated wind effect on the drifting speed and course of the buoys is almost negligible in the Kuroshio region. Hence, the trajectories of our buoys can be considered to indicate the real flow.

The gross feature of flow pattern depicted by the buoys trajectories is generally in agreement with the classical concept of ocean circulation. However, many unexpected mesoscale perturbations are found in the general flow pattern, which suggests vigorous activities of eddies and meanders. One of surprising behaviour is the cyclonic revolutions which continued for approximate 200 days in the area east of Okinawa Island. The existance of the cold eddy suggested by the buoy's cyclonic movement was confirmed by later hydrographic observations. It is the first time such a cold eddy was detected in this area.

Buoy tracking proved that it is a very useful method for measuring surface currents, especially in regions where usual ship observation is ineffective, and our knowledge about ocean currents is still meager.
\end{abstract}

\section{Introduction}

Since the first deployment in 1975, use of satellite-tracked drifting buoy as a method for collecting environmental data has been increasing. Among several applications of drifting buoy, experiments for the surface current measurement have been widely carried out in various region of the world ocean; for instance, in the Gulf Stream including associated rings (Kirwan et al., 1976; Richardson et al., 1977; Richardson, 1980), the Alaskan Stream (Reed, 1980), the eastern North Pacific (Kirwan et al., 1978) and the area southwest of Australia (Cresswell et al., 1978). Their experiments proved that buoy tracking is greatly effective for detecting the ocean current, and revealed interesting feature of flow pattern which the conventional ship observation could not, and perhaps would not, find. The successful result in experiment is mainly owing to buoy's capability to obtain continuous data remotely for a long time.

The Kuroshio, one of the strongest westem boundary current, has important effect on several

* Oceanographic Division 
problems in the vicinity of Japan, such as finding an economical ship route, change of fishing grounds and maybe variation of climate, through the fluctuation of its flow pattern. However, the dynamical mechanisms of path fluctuation in time and space is not completely clear. Therefore, it is expected that the continuous and detailed feature of the Kuroshio obtained from drifting buoys, would be greatly helpful to the study for clarifying the mechanisms of fluctuation.

In the Kuroshio region, there had been only two experiments with drifter until 1979. One was made in 1976 in a cold ring southeast of Japan and the Kuroshio Extension (Cheney et al., 1980). The other was made in 1977 under the conduct of A. D. Kirwan, and in this experiment four drifting buoys were deployed in the Kuroshio south of Japan (Nishida, 1978a, b). In January 1980, the Kuroshio investigation with satellite-tracked buoys was started by the Hydrographic Department of Japan, using the ARGOS system that is described later. This experiment forms a part of the KER (Kuroshio Exploitation and Utilization Research) project that is sponsored by the Science and Technology Agency and being in the operation since 1977. The primary purpose of the experiment is to detect continuously, as long as possible, the surface current which appears to be rather complicated due to eddies and meanders. Then, nine drifting buoys have been deployed in several parts of the Kuroshio at different times.

In sections 3 and 4 of this report, the results of examination about position accuracy and of the estimated wind effect on our buoy are given, respectively. The trajectories of the buoys are described in section 5 , with the preliminary discussion on the current condition.

\section{ARGOS System}

A description of the ARGOS system is made here only briefly since detailed one is given in ARGOS User's Guide. This system, established in 1974, collects and disseminates environmental data which is transmitted to satellite from fixed or mobile platforms in air or the earth surface, under the co-operation between NASA, NOAA and CNES. Its practical operation was started in 1978 and will be carried on until 1985 at least.

Position of platform is determined by calculation of the Doppler shifts on the signal which is transmitted from platform to the satellite ${ }^{(1)}$ every near 1 minute. The signal, whose carrier frequency is $401.65 \mathrm{MHz}$ fixed, contains sensor messages and platform's identification number (ID. No.). The satellite has DCS (Data Collection System) on the board, and its orbit is polar sunsynchronous with about 101 minutes period. Position and sensor messages are reassembled and stored in the satellite memory for transmitting back to the telemetory stations, and then forwarded to the Data Processing Center in Toulouse, France. From there, the processed results are disseminated to users in the forms of magnetic tape, telex, print-out etc.. In FGGE (First GARP Global Experiment) program, under the favor of this ARGOS system, more than 350 drifting platforms have been deployed mainly in the southern hemisphere where meteorological and oceanological knowledge had been relatively limited.

\section{The Buoy}

The buoy used for tracking is designed by HERMES Electronic Ltd. (Canada) equipped

(1) In the ARGOS system, TIROS-N and NOAA-6 had been used until TIROS-N failed to work in late February 1981. NOAA-7, instead of TIROS-N, is in operation since July 1981. 


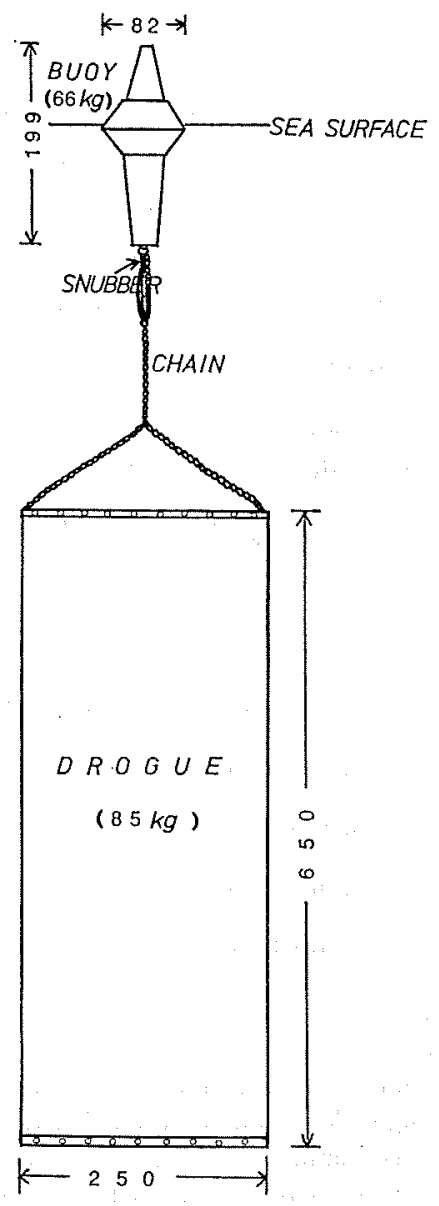

Figure 1 Appearance of drifting buoy. Length is in $\mathrm{cm}$, and weight is in air

with PTT (Platform Transmit Terminal) manufactured by HANDAR (U.S.A.), and has two sensors for near-surface water temperature and battery voltage of PTT. Appearance of the buoy is sketched in Figure 1. A "windowshade" type drogue made of sail-cloth is attached to the buoy with chains and rubber bands as a snubber, in order to weaken the wind effect on drifting speed/ course of the buoy. Estimation of wind effect, which is necessary to infer the current from the buoy trajectory, is made as follows.

According to Kirwan et al. (1975), when buoy is drogued at the surface drifting velocity (V) of buoy system is

$$
\mathrm{V}=\left(\mathrm{V}_{S}+\mathrm{K}^{1 / 2} \mathrm{~V}_{a} /\left(1+\mathrm{K}^{1 / 2}\right)\right.
$$

in a steady state, where

$$
\mathrm{K}=\rho_{a} \mathrm{C}_{D a} \mathrm{~A}_{a} / \rho_{S} \mathrm{C}_{D S} \mathrm{~A}_{S} .
$$

$\mathrm{V}_{S}$ and $\mathrm{V}_{a}$ are the velocity vectors of surface current and of wind acting on the dry portion of buoy. $\rho, \mathrm{C}_{D}$ and $\mathrm{A}$ are the fluid density, the drag coefficient and the sectional area of exposed por- 
tion to the fluid. Suffixes " $a$ " and " $S$ " denote air and sea-water respectively. It is assumed here that the buoy system consists of only two parts as dry portion and wetted portion, that the drag on chains and rubbers is negligible, and that the drogue is always normal to the current direction in upright state. Then, it is calculated as $\mathrm{K}=1.35 \times 10^{-5}$ (Table 1 ). When the surface current speed is fixed as 1 knot, results of application (1) to our buoy at arbitrarily selected wind speed is shown in Table 2 . The value

Table 1 Hydrodynamic constants of drifting platform used in the experiment

\begin{tabular}{clll}
\multicolumn{3}{c|}{ BUOY } & \multicolumn{1}{c}{ DROGUE } \\
\hline$A_{a}=0.31$, & $C_{D a}=0.68$, & $\rho_{a}=1.2 \times 10^{-3}$ & $A_{s}{ }^{\prime}=16.25, \quad C_{D S}^{\prime}=1.12$ \\
$A_{S}=0.46$, & $C_{D S}=0.68, \quad \rho_{S}=1.0$ & $\rho_{s}^{\prime}=1.0$ \\
\hline \hline
\end{tabular}

Table 2 Application of equation (1) to the drifting plaftorm

\begin{tabular}{c|c|c|c}
\hline$\left|V_{a}\right|(\mathrm{knot})$ & $|\mathrm{V}|(\mathrm{knot})$ & $\theta_{\max }($ degree $)$ & $10^{2} \times\left|\mathrm{V}-\mathrm{V}_{S}\right| /|\mathrm{V}|(\%)$ \\
\hline 50 & $0.81 \sim 1.18$ & 10.7 & 23.1 \\
\hline 20 & $0.92 \sim 1.07$ & 4.2 & 8.4 \\
\hline 10 & $0.96 \sim 1.03$ & 2.1 & 4.2 \\
\hline 5 & $0.98 \sim 1.01$ & 1.1 & 2.3 \\
\hline
\end{tabular}

$\left|V_{a}\right|$ : wind speed

$|V|$ : drifting speed of buoy system

$\left|V_{s}\right|$ : surface current speed and fixed as 1.0 knot

$C_{\max }:$ maximum angle deviation between drifting vector and current vector

$10^{2} \times\left|\mathrm{V}-\mathrm{V}_{s}\right| /|\mathrm{V}|:$ maximum percentage error between speed of buoy system and surface current (according to Kirwan et al., 1975)

of 1 knot is a typical current speed in the Kuroshio region, while more than 2 knot is usually experienced in the main part of the Kuroshio. Since the exposed portion of buoy on which wind acts is only $80 \mathrm{~cm}$ hihg, wind speed $\left|\mathrm{V}_{a}\right|$ needs to be estimated at such height. Usually, wind speed in the ocean field is below 40 50 knot and it is measured at about $10 \mathrm{~m}$ height above the sea surface. In general, wind becomes logarithmically weak as approaching to the surface; for example, wind speed at $10 \mathrm{~m}$ height is reduced to about $30 \%(20 \%)$ at $1 \mathrm{~m}(50 \mathrm{~cm})$ height above the surface. Thus, 10 knot is a reasonable magnitude of wind speed at near the sea surface. As shown in Table 2, it can be considered that wind effect on the buoy is negligible in the Kuroshio region, and that the buoy trajectory, therefore, indicates the real surface current. A comparison between the buoy trajectory and progressive vector of geostrophic wind shows that above consideration is adequate (section 5.3). Hence, in the description of trajectories in this report, wind data is not dealt with except above one case study.

\section{Accuracy of Buoy Position}

The position accuracy is quite essential for buoy experiment. When the buoy is located on the earth surface, the accuracy is examined here by comparing the satellite-determined position 
with the known position. On the other hand, when the buoy is drifting on the sea surface, the accuracy could not be examined by the same way as above. Instead, a tentative comparison is made between the satellite-determined position of the buoy on board sailing ship and the ship position determined by Loran-C method.

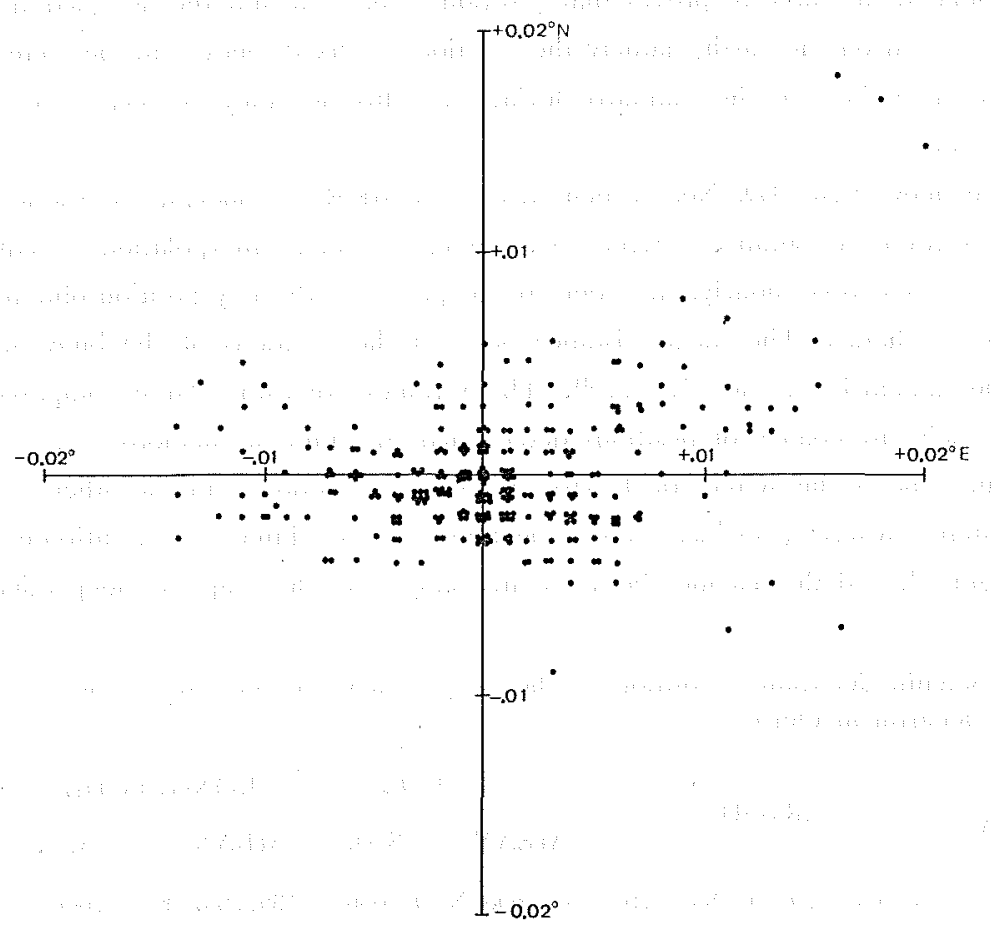

Figure 2 Scatter diagram of positions for nine buoys which were located on the Hydrographic Department Office. The data $\left(-0.034^{\circ} \mathrm{N}, 0.007^{\circ} \mathrm{E}\right.$ for 2022) is not plotted.

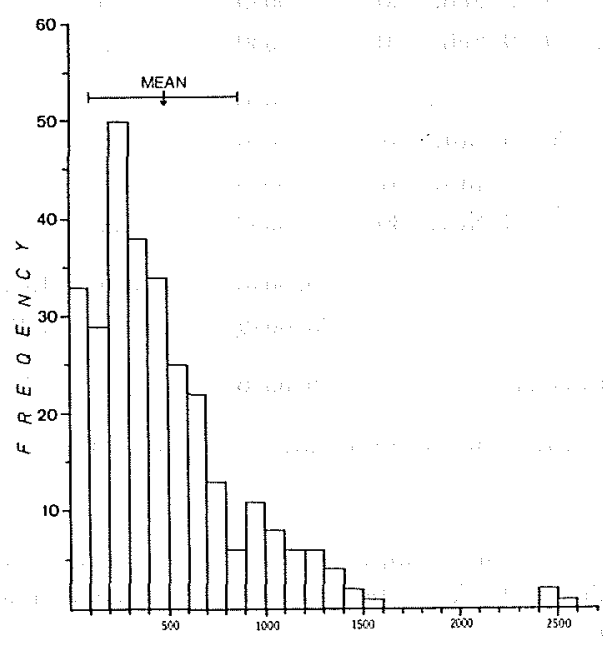

Figure 3 Histogram of distance between the known position and buoy's position determined by the satellites. The data of $3735 \mathrm{~m}$ for 2022 is excluded. 
Nine buoys were located at different times on the Hydrographic Department Office, whose position is $35.6646^{\circ} \mathrm{N}, 139.7654^{\circ} \mathrm{E}$ referred to the earth ellipsoid WGS-72. Figure 2 shows the scattering of the buoys' position from the known position on which the buoys were located, and Figure 3 is the histogram of the calculated distance between the known position and the buoy's position. The results, tabulated in Table 3, proves that position error is within the designed limit of $2 \mathrm{~km}^{(2)}$ when platform is fixed on the earth; namely the position of fixed buoy can be determined within about $1.7 \mathrm{~km}$ at three times of the standard deviation. This accuracy is very good for measuring the surface current.

For the buoy 2020 (ID. No.) which was on board R/V Takuyo, its position is compared with the ship position by Loran-C (Figure 4). Here, the linear-interpolation is required for ship position which was recorded hourly, in order to compare it with buoy position obtained at intervals of 100 minutes 11 hours. The mean distance between the positions of the buoy and the ship is $2.5 \mathrm{~km}$, with the standard deviation $1.5 \mathrm{~km}^{(3)}$. These values are rather large compared to those on the earth. For such discrepancy of positions determined by different methods, two explanations are apt to be given. One is the systematical error in Loran-G position, and the other is the employ of linear-interpolaiton. However, no bias tend to be found in the difference of latitude and longitude as shown in Figure 4, and the distance between the buoy and the ship is independent of minutes

Table 3 Satellite-determined position of the buoy which was located on the Hydrographic Department Office

\begin{tabular}{|c|c|c|c|c|c|c|c|c|}
\hline \multirow{2}{*}{$\begin{array}{l}\text { ID. } \\
\text { No. }\end{array}$} & \multirow{2}{*}{$\begin{array}{l}\text { No. of } \\
\text { DATA }\end{array}$} & \multirow{2}{*}{ PERIOD } & \multicolumn{2}{|c|}{ LATITUDE } & \multicolumn{2}{|c|}{ LONGITUDE } & \multirow{2}{*}{\multicolumn{2}{|c|}{$\begin{array}{l}\text { DISTANCE } \\
(\mathrm{m}) \\
\text { MEAN S.D. }\end{array}$}} \\
\hline & & & MEAN & S.D. & MEAN & S.D. & & \\
\hline 2020 & 40 & 16 Dec. '79-25 Dec. '79 & $35.6658^{\circ} \mathrm{N}$ & $0.0036^{\circ}$ & $139.7657^{\circ} \mathrm{E}$ & $0.0060^{\circ}$ & 506 & 465 \\
\hline 2021 & 33 & 16 Dec. '79-25 Dec. '79 & 6654 & 34 & 7660 & 58 & 478 & 450 \\
\hline \multirow[t]{2}{*}{2022} & 29 & 17 Dec. '79-25 Dec. '79 & 6643 & 68 & 7654 & 52 & 612 & 649 \\
\hline & $28^{*}$ & 17 Dec. '79-25 Dec. '79 & $6655^{*}$ & $26^{*}$ & $7654^{*}$ & $53 *$ & $500^{*}$ & $273^{*}$ \\
\hline 2023 & 48 & 16 Dec. '79-19 Feb. '80 & 6649 & 26 & 7651 & 52 & 442 & 332 \\
\hline 2024 & 55 & 17 Dec. '79-19 Feb. '80 & 6650 & 37 & 7667 & 54 & 483 & 439 \\
\hline 2025 & 26 & 20 Oct. ' $80-11$ Nov. '80 & 6638 & 22 & 7655 & 70 & 561 & 393 \\
\hline 2026 & 22 & 20 Oct. '80- 8 Jan. '81 & 6646 & 20 & 7651 & 48 & 407 & 270 \\
\hline 2027 & 25 & 20 Oct. '80- 8 Jan. '81 & 6648 & 17 & 7644 & 57 & 449 & 328 \\
\hline 2029 & I4 & 20 Oct. ' $80-10$ Nov. ' 80 & 6632 & 24 & 7656 & 71 & 633 & 336 \\
\hline \multirow{2}{*}{ Total } & 292 & & 35.6648 & 0.0036 & 139.7656 & 0.0058 & 497 & 432 \\
\hline & $291^{*}$ & & $35.6649^{*}$ & 0.0030 & $139.7656^{*}$ & $0.0058^{*}$ & $486^{*}$ & $388^{*}$ \\
\hline \multicolumn{3}{|c|}{ FIXED PODITION } & 35.6646 & & 139.7654 & & & \\
\hline
\end{tabular}

* Value is calculated when the position data $35.631^{\circ} \mathrm{N}, 139.764^{\circ} \mathrm{E}$ for the buoy 2022 is excluded.

(2) This value is calculated on assumption that PTT is highly stable $\left(2 \times 10^{-9}\right.$ over 20 minutes.) When PTT's stability is $10^{-8}$, position accuracy is calculated as within $3 \mathrm{~km}$ at three times of standard deviation.

(3) The same comparison are made for the buoys 2021 and 2022 which were on board Takuyo together with 2020 until their preceding launches, and quite similar results to that for 2020 are obtained. 


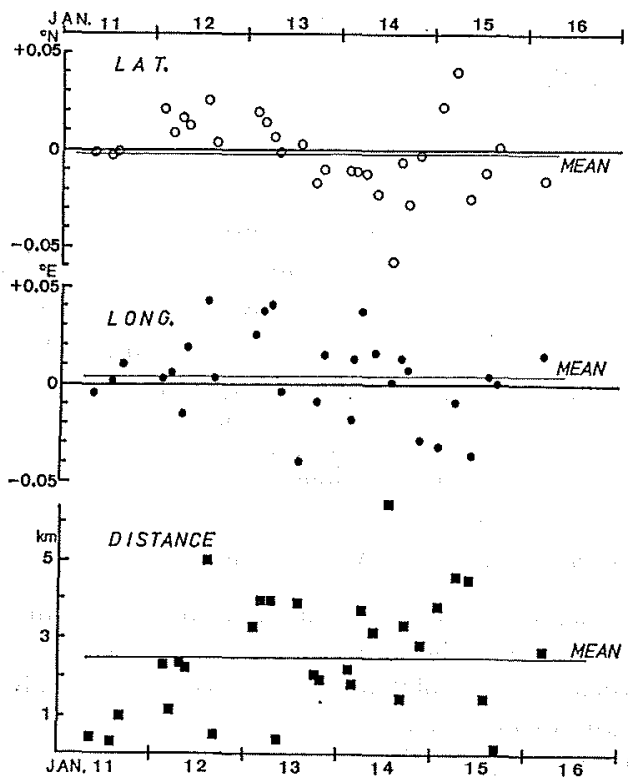

Figure 4 Difference of satellite-determined positions of the buoy from ship positions determined by Loran-G method. (upper) latitude, (middle) longitude, (lower) distance between both positions.

at which comparison is made. Thus, both explanations are rejected. While it is not defined that either determination introduced larger error, the position determined by the satellites seemed to have the accuracy comparable to one by Loran-C method. This accuracy is still satisfactory for measuring the surface current in the open ocean.

\section{Trajectories}

The buoy trajectories are described here for the period from January 1980 to May 1981. The list of the buoys that the Hydrographic Department has deployed is shown in Table 4, and the composite trajectories of all buoys are described in Figure 5. The gross feature of flow pattern depicted by the overall trajectories, agrees with the classical concept of the ocean circulation in the western North Pacific. That is,

1) In the area south of Honsyu, buoys are flowing on the Kuroshio, or the cyclonic and the anticyclonic current associated with the Kuroshio cold eddy and the warm eddy.

2) To the east of Japan, two buoys flow eastwardly in the Kuroshio Extension or the North Pacific Current.

3) Two buoys which crossed over the Izu-Ogasawara Ridge nearly at $30^{\circ} 30^{\prime} \mathrm{N}, 142^{\circ} \mathrm{E}$, show a tendency to follow the subtropical gyre.

However, in a mesoscale aspect, the trajectories are very complicated as exemplified as follows. Many loops are seen in the area east of Okinawa Island. One of the buoys has been staying for about half a year in the region $31^{\circ} \sim 34^{\circ} \mathrm{N}$ and $154^{\circ} \sim 160^{\circ} \mathrm{E}$, not flowing on the Kuroshio Extension. At near $172^{\circ} \mathrm{E}$, two buoys move separately in the quite opposite directions (northward and southward), though their arrival time at that place are different by about 5 months. In the follow- 
Table 4 List of the buoys used in the experiment

\begin{tabular}{|c|c|c|c|c|c|c|c|c|}
\hline \multirow{2}{*}{$\begin{array}{c}\text { No. of } \\
\text { BUOY } \\
\text { (ID. No.) }\end{array}$} & \multicolumn{4}{|c|}{ DEPLOYMENT } & \multicolumn{4}{|c|}{ LAST REGORD } \\
\hline & DATE & \multicolumn{2}{|c|}{ POSITION } & AREA & DATE & \multicolumn{2}{|c|}{ POSITION } & $\begin{array}{l}\text { DAYS in } \\
\text { OPER- } \\
\text { ATION }\end{array}$ \\
\hline I (2020) & 16 Jan. ' 80 & \multicolumn{2}{|c|}{$31^{\circ} 10^{\prime} \mathrm{N}, 134^{\circ} 47^{\prime} \mathrm{E}$} & Warm Eddy & 13 May '81 & \multicolumn{2}{|c|}{$25^{\circ} 08^{\prime} \mathrm{N}, 176^{\circ} 06^{\prime} \mathrm{E}$} & 484 \\
\hline II $(2021)$ & 14 Jan. ' 80 & $32^{\circ} 57^{\prime}$ & $138^{\circ} 15^{\prime}$ & Cold Eddy & 18 Oct. ' 80 & $43^{\circ} 03^{\prime}$ & $177^{\circ} 26^{\prime} \mathrm{W}$ & 279 \\
\hline II (2022) & 14 Jan. '80 & $32^{\circ} 55^{\prime}$ & $137^{\circ} 45^{\prime}$ & Cold Eddy & $30 \mathrm{Jan}$. ' 80 & $33^{\circ} 39^{\prime}$ & $136^{\circ} 56^{\prime} \mathrm{E}$ & $16^{*}$ \\
\hline IV (2023) & 11 Mar. ' 80 & $27^{\circ} 17^{\prime}$ & $126^{\circ} 15^{\prime}$ & & 14 May '81 & $22^{\circ} 19^{\prime}$ & $138^{\circ} 32^{\prime}$ & 430 \\
\hline$\nabla(2024)$ & 11 Mar. ' 80 & $27^{\circ} 26^{\prime}$ & $126^{\circ} 07^{\prime}$ & Kuroshio to & 6 May' 80 & $32^{\circ} 17^{\prime}$ & $130^{\circ} 00^{\prime}$ & $57 * *$ \\
\hline II (2025) & $6 \mathrm{Feb} . ' 81$ & $27^{\circ} 06^{\prime}$ & $126^{\circ} 27^{\prime}$ & $\begin{array}{l}\text { the east of } \\
\text { Okinawa }\end{array}$ & & & & \\
\hline VII (2026) & 6 Feb. '81 & $27^{\circ} 13^{\prime}$ & $126^{\circ} 18^{\prime}$ & Island & & & & \\
\hline 听 $(2027) * * *$ & 6 Feb. ' 81 & $27^{\circ} 19^{\prime}$ & $126^{\circ} 09^{\prime}$ & & & & & \\
\hline I $(2029)$ & 26 Feb. ' 81 & $30^{\circ} 28^{\prime}$ & $137^{\circ} 30^{\prime}$ & Warm Eddy & & & & \\
\hline
\end{tabular}

* This short lifetime might be due to a collision with ship for the reasons that (1) the last position is obtained in one of the main ship route (2) battery voltage was in good order (3) the last recorded time is $20 \mathrm{~h} 08 \mathrm{~m}$, but the satellites usually cover the area adjacent to Japan in midnight to morning.

** Drifted ashore on Amakusa-Simosima in Kyusyu.

*** Recovered by P/V Asizuri on April 25 when drifting without drogue.

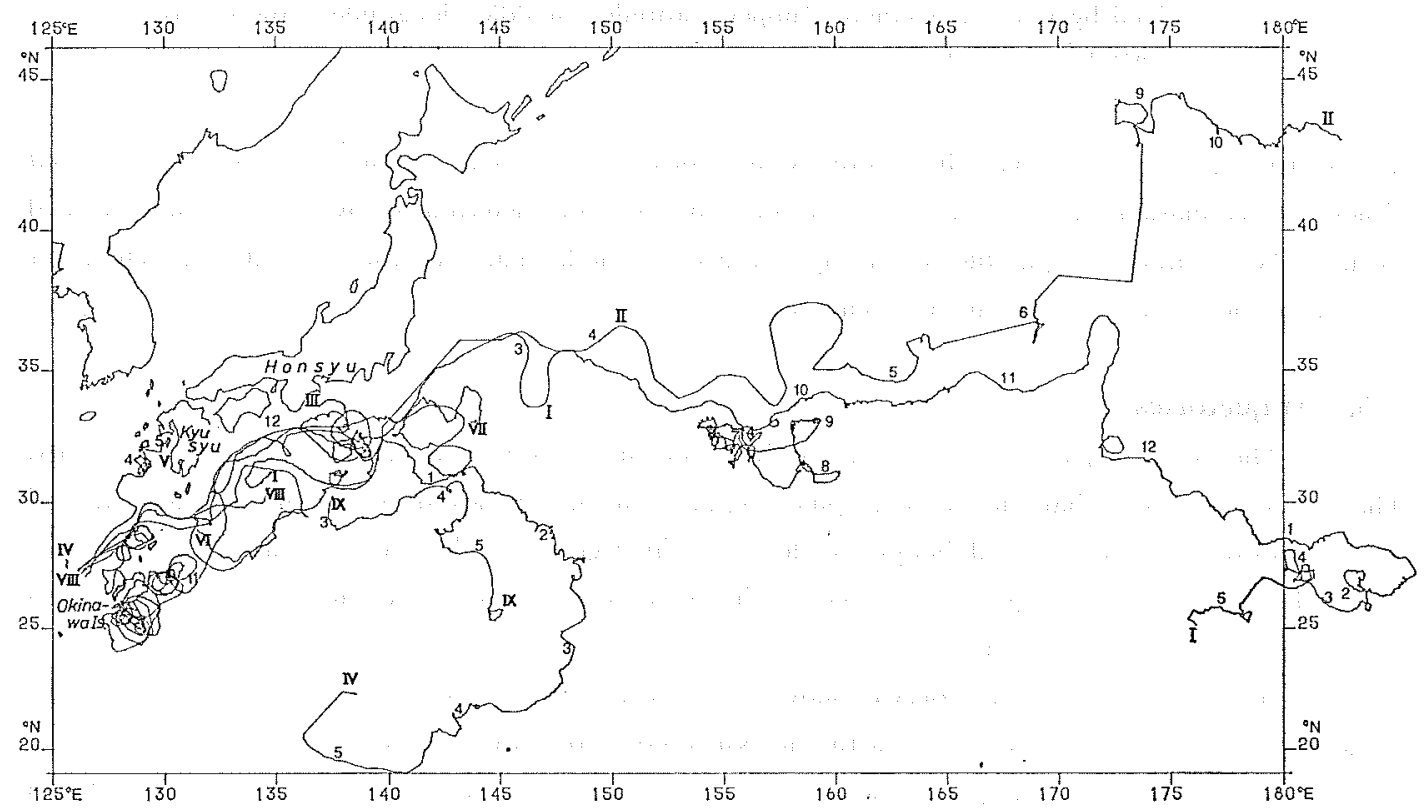

Figure 5 Composite trajectories of nine buoys in the period from 14 January 1980 to 15 May 1981. Numeral indicates the position at the first day of each month.

ing sections, the description are made of the interesting behavior of the buoys, such as above examples, in several regions.

5-1 West of Amami Islands

Five drifting buoys were launched into the main part of the Kuroshio to the northwest of Okinawa Island (Figure 6); two buoys (IV and V) were launched on 11 March 1980 and three (VI, VII and VIII) on 6 February 1981. Out of five buoys, only two (VI and VII) flowed 
downstream on the Kuroshio to enter into the Pacific Ocean south of Japan. However, other three buoys (IV, V and VIII) showed somewhat unexpected trajectories.

Buoy IV moved downstream in the Kuroshio until 5 days after the launch, but made 1.5 clockwise loops with the diameter of about $70 \mathrm{~km}$ and with the period of about 7 days in the area northwest of Amami-Osima. After that, it flowed to the southwest in the opposite direction to the Kuroshio. Buoy VIII also made two clockwise loops with diameters (periods) of $70,90 \mathrm{~km}$ (6, 7 days) on the southwest and west of Amami-Osima respectively. It is thought that southwestward current exists along the westside of Amami Islands as suggested, for example, by the mean distribuiton of surface temperature in winter (Figure 7). However, it seemed to be the first experi-

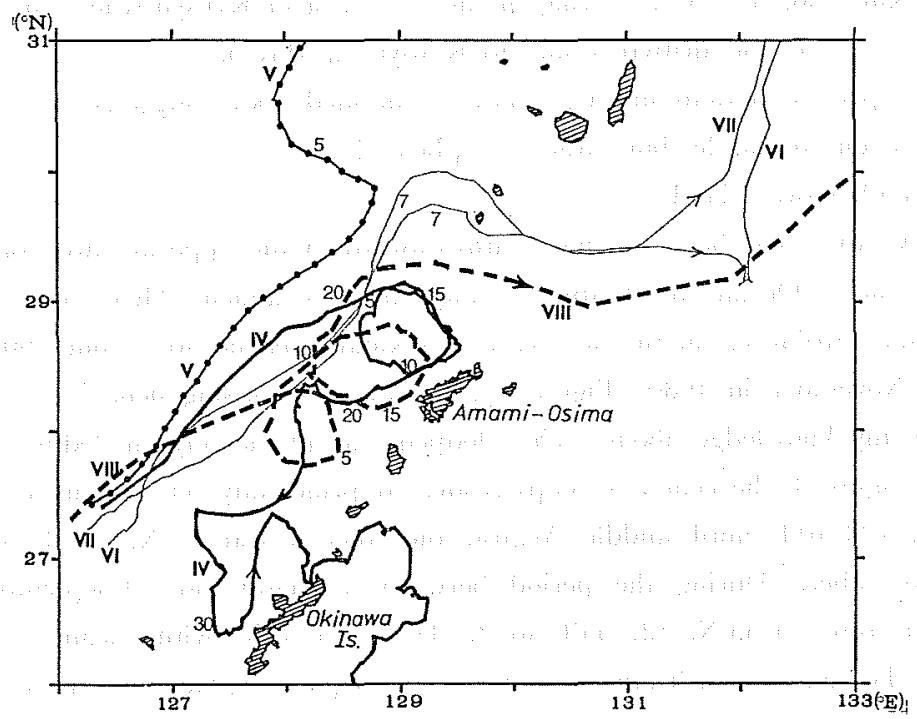

Figure 6 Trajectories of five buoys launched in the Kuroshio to the northwest of Okinawa Island. Numeral is days which passed since the launch.

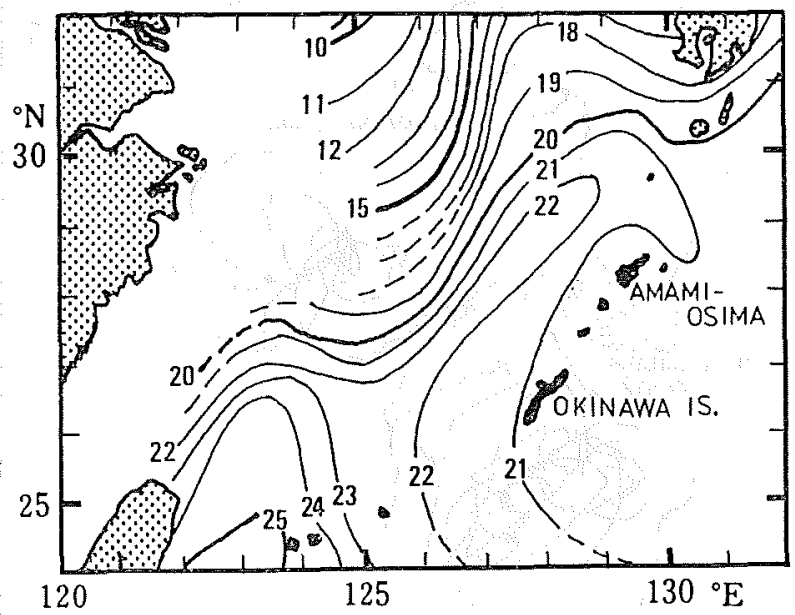

Figure 7 Monthly mean surface temperature in March. From Marine Environmental Atlas, Northwestern Pacific Ocean II; compiled by Japan Oceanographic Data Center and published by Japan Hydrographic Association (1978). 
ence to see a looped current in this region. Then, with respect to above looped motions of the buoys, some questions are here. Is looped current usually in existance at least in winter, or is it also in existance in other seasons? Whether a clockwise loop indicates a warm eddy? Do two loops of buoy VIII indicate two different eddies? The answers to these questions may be given later by statistical analysis of observation data.

Buoy V had been traveling on the Kuroshio with the speed of about 2.5 knot, but suddenly changed its course to the left in near the $90^{\circ}$ direction, at 4 days after its launch. It appears to be an unlooked-for and interesting behavior that the buoy failed to be in the main Kuroshio within a rather short time (half a day), though the reason for sudden change of course is unknown. Buoy $\mathrm{V}$, after it left the Kuroshio, had been staying in the area west of Kyusyu where the depth is shallower than $800 \mathrm{~m}$ in most part, and drifted ashore to Kyusyu on May 6.

The unexpected motions of three buoys mentioned above suggests that the region west of Amami Islands is not so simple, but rather complicated one.

\section{5-2 East of Okinawa Island}

Buoy IV, that had been moving southwestward in the opposite direction to the Kuroshio, entered into the Pacific Ocean on 20 April, 40 days after its launch. Thereafter, the buoy continued to execute cyclonic revolutions in the area east of Okinawa Island for about 190 days, from early May to middle November in 1980 (Figure 8). It was a surprising behavior of the buoy because we had not had any knowledge about such a looped current, namely an "eddy" as described next, in this area. In Figure 8, the center of loops is located principally on two distinctive positions; one is near $25^{\circ} 20^{\prime} \mathrm{N}, 128^{\circ} 40^{\prime} \mathrm{E}$ until middle August, the other is near $27^{\circ} \mathrm{N}, 130^{\circ} \mathrm{E}$ from early September to early November. During the period between 31 August and 10 September, the buoy transfered its position from $25^{\circ} 55^{\prime} \mathrm{N}, 127^{\circ} 55^{\prime} \mathrm{E}$ to $27^{\circ} 05^{\prime} \mathrm{N}, 130^{\circ} 15^{\prime} \mathrm{E}$ with mean speed of $45 \mathrm{~km} /$ day (1 knot). As to the cause of such abrupt transfer, no adequate explanations are found yet. Excluding above transient time, averaged radius and speed of revolutions are approximately $70 \mathrm{~km}$ and 40 $\mathrm{cm} / \mathrm{sec}$.

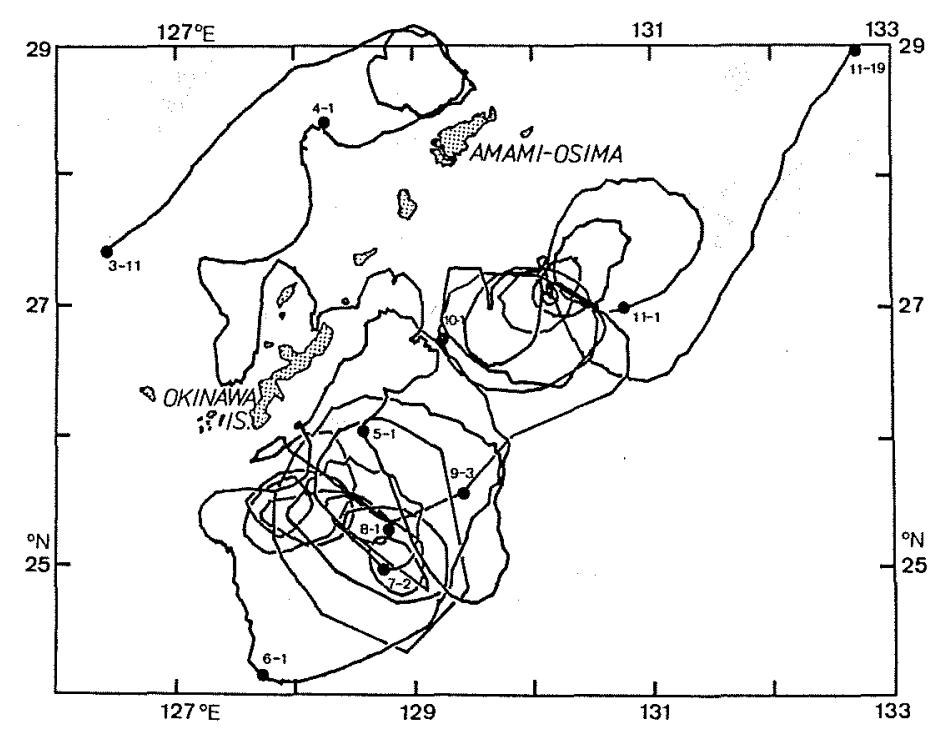

Figure 8 Trajectory of the buoy IV in the period from 11 March to 19 November 1980 


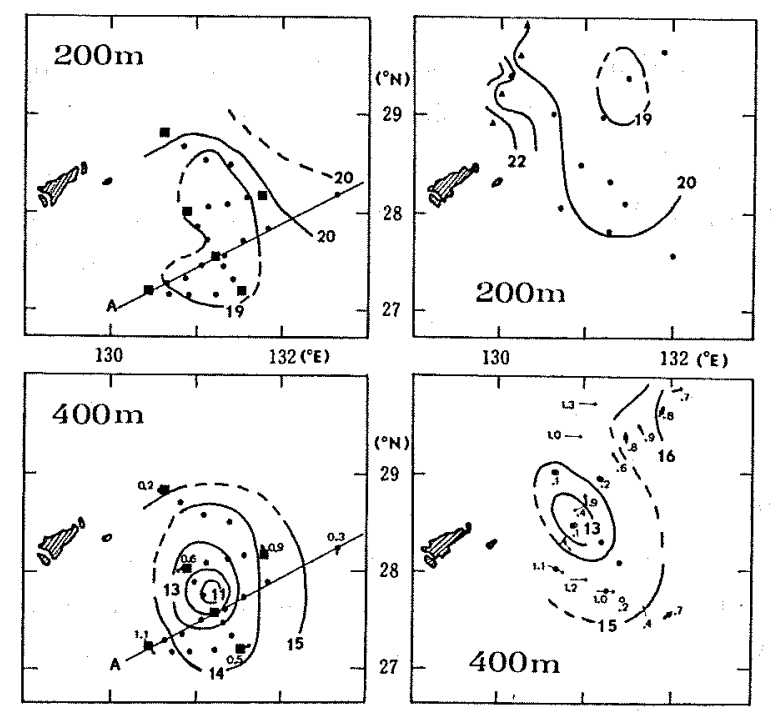

Figure 9 Temperature and current velocity (by GEK, in knot) around the cold eddy. Leftside graphs are results of observation in 23-25 November 1980 (Syoyo), and rightside in 11-14 December 1980 (Takuyo). - is station of serial observation, and $\bullet, \Lambda$ are XBTs.

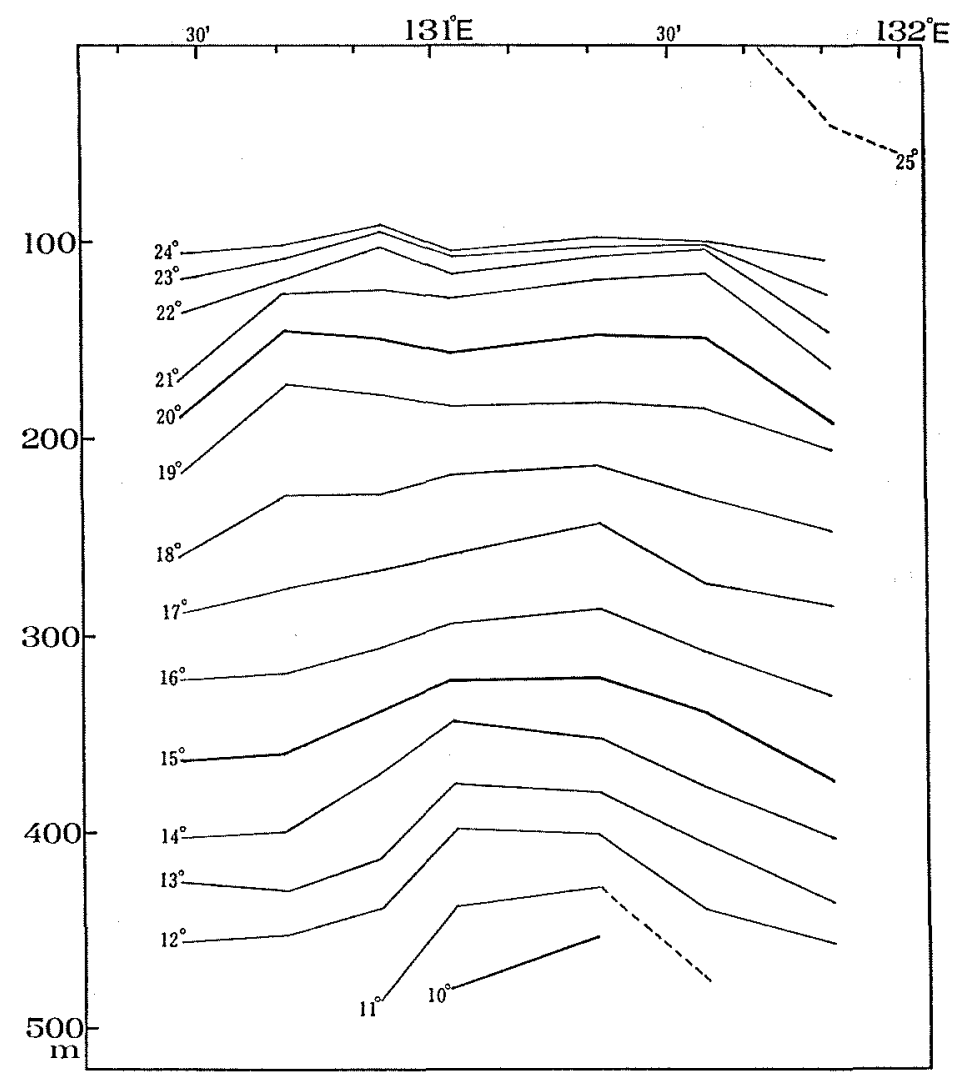

Figure 10 Temperature profile on the section "A" shown in leftside graphs of Figure 9. 
As revolving trajectories had suggested the existance of a cold eddy, this was confirmed by the hydrographic observations in November and December of 1980, by R/V Syoyo and Takuyo respectively. Some of the results of both observations are shown in Figures 9 and 10. The feature of the cold eddy is depicted in the maps of horizontal temperature (Figure 9), though it is rather ambiguously at $200 \mathrm{~m}$ depth. It is shown in Figure 10 that the mixed layer develops to extend to the depth of $100 \mathrm{~m}$ in the whole of cold eddy region. The eddy, then, was hardly detectable from the observation data which were obtained in upper part than $100 \mathrm{~m}$, and it could be revealed only by the drifting buoy.

From Figure 9, it is shown that eddy's center traveled a distance of $85 \mathrm{~km}$ to the north between two observation periods, with concurrent increase of temperature at the center as much as $2^{\circ} \mathrm{C}$. Further, eddy-tracking with XBTs was tried once more in 15-17 January 1981 by Takuyo. At that time, a cold water area was found in ellipse-like shape with diameters of near 80 and $120 \mathrm{~km}$. The central portion of this cooler area is situated on $28^{\circ} 30^{\prime} \mathrm{N}, 133^{\circ} \mathrm{E}$ with about $15^{\circ} \mathrm{C}$ temperature. If this is the same eddy as that observed in December 1980, it must have moved eastward as much as $200 \mathrm{~km}$ accompanied with $2^{\circ} \mathrm{C}$ increase of temperature at the center by one month. A series of increase in temperature may indicate the decaying process of the cold eddy since November 1980.

Buoy IV made an unexpected and remarkable discovery of the cold eddy that had not been known. In respect to this eddy, however, there are several problems. For example, how long is its lifetime? Had the eddy been formed at the region where it was observed, or had it traveled from other place at which it was previously formed? Does such an eddy often exist in this region, although only sparse observaiton had not been able to detect it? Additionally, were two different eddies in existance as suggested by two distinct locations of the center of looped motion? These problems will have to be discussed later. However, it seemed to be difficult to clarify them completely, because there has been, unfortunately, few observation to provide suitable data in the concerned area.

\section{5-3 South of Honsyu}

Since January 1980, eight buoys have worked at different periods in the area south of Honsyu, where two types of the Kuroshio path had been seen in 1980. Throughout the time from August 1975 to August 1980, the Kuroshio cold eddy which locates generally on the westside of the Izu-Ogasawara Ridge, had been staying on the south of Honsyu, and the meandered Kuroshio had been flowing surrounding the cold eddy (Nishida, 1982). Since the disappearance of the meander/ cold eddy, the Kuroshio is flowing along the south coast of Honsyu for the most of time.

On 14 January 1980, two buoys (II and III) were launched into near the center of the Kuroshio cold eddy. Buoy I was successively launched on 16 January in the warm eddy which is usually seen to the south of the Kuroshio. Figure 11 shows the trajectories of above three buoys while they had been remaining in the south of Honsyu. Buy I moved clockwise for about 22 days after the launch, but changed the course to the east missing the warm eddy. Then it traveled along the outside of the Kuroshio with mean speed of 0.8 knot until it reached the Izu-Ogasawara Ridge. When the buoy was near the Ridge, the Kuroshio had been separately flowing to form two branches (Figure 11a). Buoy I properly followed one of the branched currents, and met the Kuroshio Extension in late February.

Buoys II and III started to move cyclonically as were expected. However, buoy III stopped 

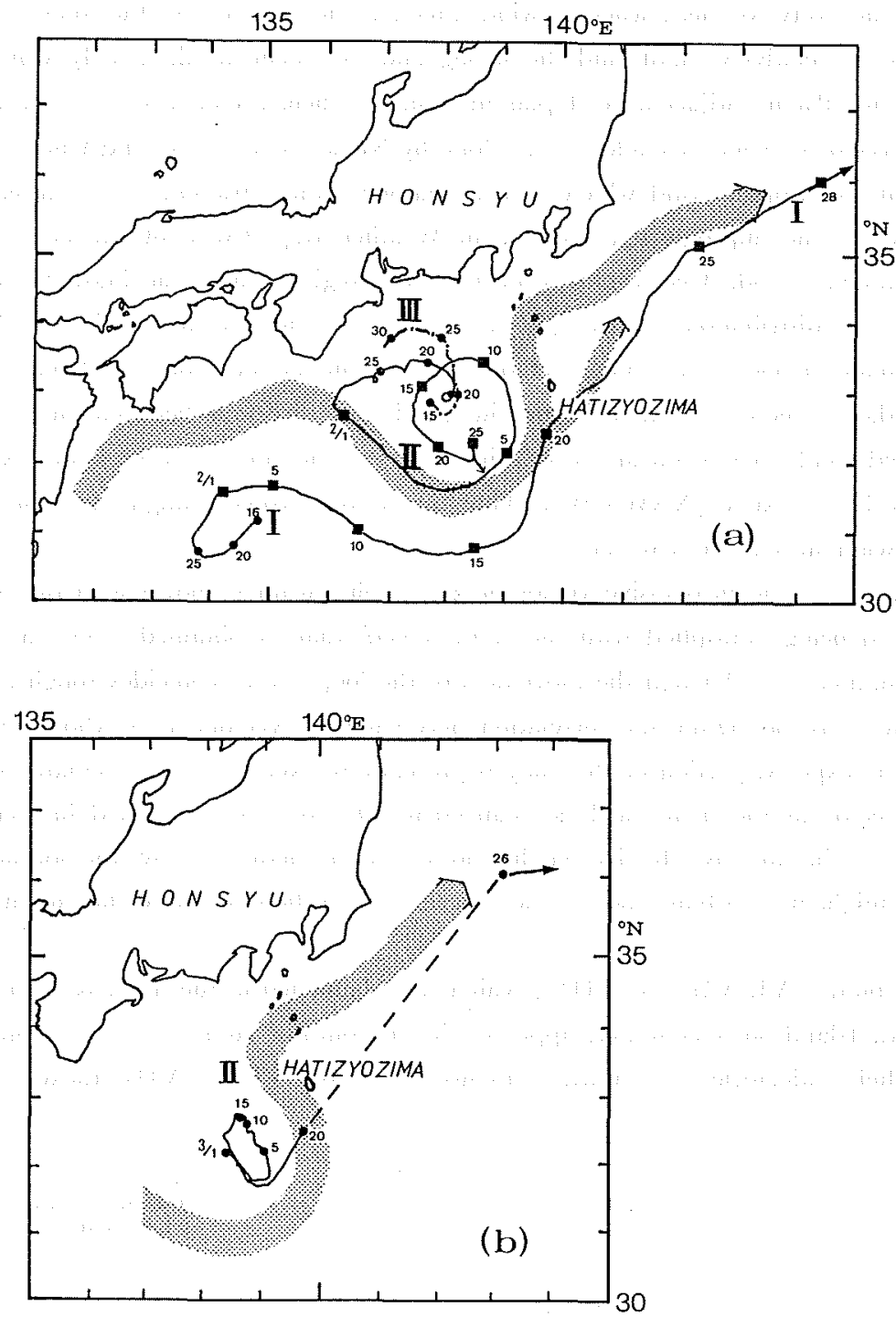

Figure 11 (a) Trajectories of the buoy I, II and III in January (•) and February of 1980 .

(b) Trajectory of the buoy II in March 1980.

Numeral shows date in each month. The Kuroshio path is according to the Prompt Report of Oceanographic Conditions published semimonthly by the Hydrographic Department of Japan. The path in (a) is from the Report No. 4 (Jan. 31-Feb. 13), and (b) from No. 6 (March 3-15).

sending messages on 30 January only 16 days after its launch (see Table 4 ). Buoy II continued to track the cold eddy making cyclonic loops for 65 days, except for 4 days (February 1-4) while the buoy was flowing in the Kuroshio with $1.5 \sim 3$ knot. After the tracking of the cold eddy, buoy II emigrated to the Kuroshio Extension one month later than buoy I.

The size of above cyclonic loops became gradually small along with southeastward movement of the loop center, and in the looping period the buoy's mean speed was about 0.5 knot. 
Here, we felt a necessity to check whether wind affected the motion of the buoy; because above speed seemed to be relatively small, and the strong and persistent wind, namely winter-monsoon, is dominant over hte Pacific adjacent to Japan in winter. Then, a comparison of the trajectory with the progressive vector of wind is made as was done by Richardson (1978) and Cheney et al. (1980). In a comparison, geostrophic wind which is idealized one without friction is used instead of real wind in the field, because the ship-reported wind in the Weather Map ${ }^{(4)}$ was not always given continuously during the examined period. Geostrophic wind over the region where the buoy II was drifting, is calculated from the distribution of atmospheric pressure at the sea surface in the Weather Map. Calculation is made at one or two times per day, during the period from 14 January to 19 March except for five days. There are few difference in speed and direction between the calculated wind and ship-reported wind; that is, mean speed (direction) of the former is 19 knot (NNW) and the latter is ranged $15 \sim 20$ knot $(\mathrm{NNW} \sim \mathrm{W})$. Thus, no serious problem might be arisen from the use of geostrophic wind instead of real one.

In Figure 12, the progressive vector of geostrophic wind is shown with the buoy trajectory, where wind speed being multiplied with the value 0.0037 that is obtained from the term $\mathrm{K}^{1 / 2}\left|\mathrm{~V}_{a}\right| /$ $\left(1+K^{1 / 2}\right)$ in equation (1). Though the movement of the loop center coincides roughly with the wind in direction, there are no significant correlation between both vectors as a whole. Since the wind which acts on the exposed portion of the buoy is probably weaker than the calculated one, the length of progressive vector in the figure will be reduced to $20 \sim 30 \%$, as mentioned in section 3 . Hence, the wind might not be directly effective on the motion of the buoy; namely, the southeastward transfer of the loop might be attributed not to the carrying of the buoy by wind, but to the movement of the cold eddy.

Three buoys (VI, VII and VIII), which were launched in the main Kuroshio to the northwest of Okinawa Island on 6 February, appeared in the south of Honsyu on 15, 16 and 28 February, respectively. Their trajectories are shown in Figure 13. Buoys VI and VIII tracked the warm eddy

TA A JECTOAY

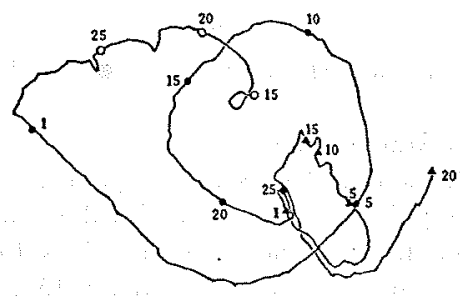

WI ND

PROGRESSIVE

VECTOR

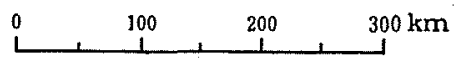

Figure 12 Trajectory of the buoy II and progressive vector of geostrophic wind during the period from 14 January to 20 February 1980 . Wind speed is multiplied with the value 0.0037

(4) The Daily Weather Maps published by the Japan Meteorological Agency. 


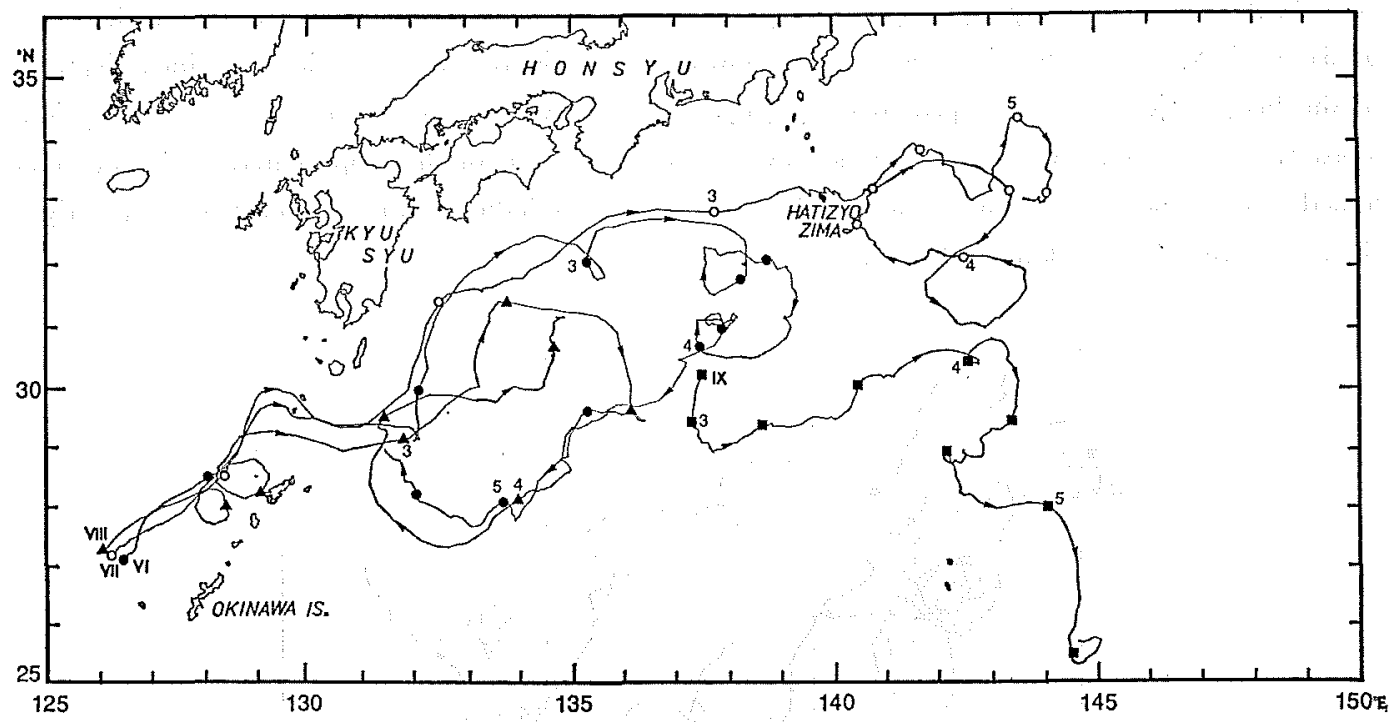

Figure 13 Trajectories of the buoys VI (e), VII (O), VIII (A) and IX ( $\mathbf{a}$ ) in the period from 6 February to 15 May 1981. Numeral indicates the position at the first day of each month. Symboled positions mean the date of 1 st, 10 th and 20 th in each month, or the date when buoy was launched

outside of the Kuroshio, and clearly depicted its external feature. Several loops which are overlapped on the large circulation of the warm eddy are interesting. Buoy VII, on the other hand, flowed along with the Kuroshio to traverse the Izu-Ogasawara Ridge through near Hatizyozima. Thereafter, it failed to go into the Kuroshio Extension, but have been staying in the area east of Hatizyozima showing a complex motion. From a series of current chart and/or temperature maps in the Prompt Report of Oceanic Conditions, it is suggested that there are no conspicuous and steady current in the region where the buoy has been staying. Instead, warmer or cooler area has been observed from time to time. Maybe, the motion of the buoy VII is controled by such oceanic conditions.

Buoy IX was deployed in the eastern part of the warm eddy. It moved to the east contrary to our expectation, and then crossed over the Ridge at almost same position $\left(30^{\circ} 30^{\prime} \mathrm{N}, 142^{\circ} \mathrm{E}\right)$ as that buoy IV passed 3 months before (Figure 5). One of four drifters which were launched by A. D. Kirwan into the Kuroshio on the east of Kyusyu in 1977, passed over the Ridge at $28^{\circ} \mathrm{N}$, $142^{\circ} \mathrm{E}$, and after that it followed the subtropical gyre until it reached the island of Philippine (Nishida, 1978a, b). Buoys IV and IX are following the gyre in a manner similar to Kirwan's drifter.

Looking over the buoys' behavior after the traversing the Izu-Ogasawara Ridge, it is speculated that they can be classified into three types. That is, (1) flowing to the east on the Kuroshio Extension, (2) if crossed over the Ridge at near $30^{\circ} \mathrm{N}$, flowing to the southeast or south-southeast in a part of the subtropical gyre, (3) spending a time in the area east of Hatizyozima until it emigrates to either the Kuroshio Extension or the current associated with the subtropical gyre.

\section{5-4 East of Japan}

Two buoys ( $\mathrm{I}$ and II) met the Kuroshio Extension. Buoy I followed astriking meander at $146^{\circ}-147^{\circ} \mathrm{E}$, and thereafter it moved to the east-southeast with mean speed of 1 knot to reach 
near $32^{\circ} \mathrm{N}, 156^{\circ} \mathrm{E}$ by early April (Figure 5). However, the buoy stayed for half a year in the region of $31^{\circ} \sim 34^{\circ} \mathrm{N}, 154^{\circ} \sim 160^{\circ} \mathrm{E}$ without going downstream. Figure 14 shows the magnified depiction of the buoy trajectory from April to early July. From early April to 20 June, a series of cyclonic loops were executed along with the northwesteward movement of the loop center. It is not determined due to the lack of data whether these looped tracks indicates the existance of cold eddy as the case in the east of Okinawa Island.

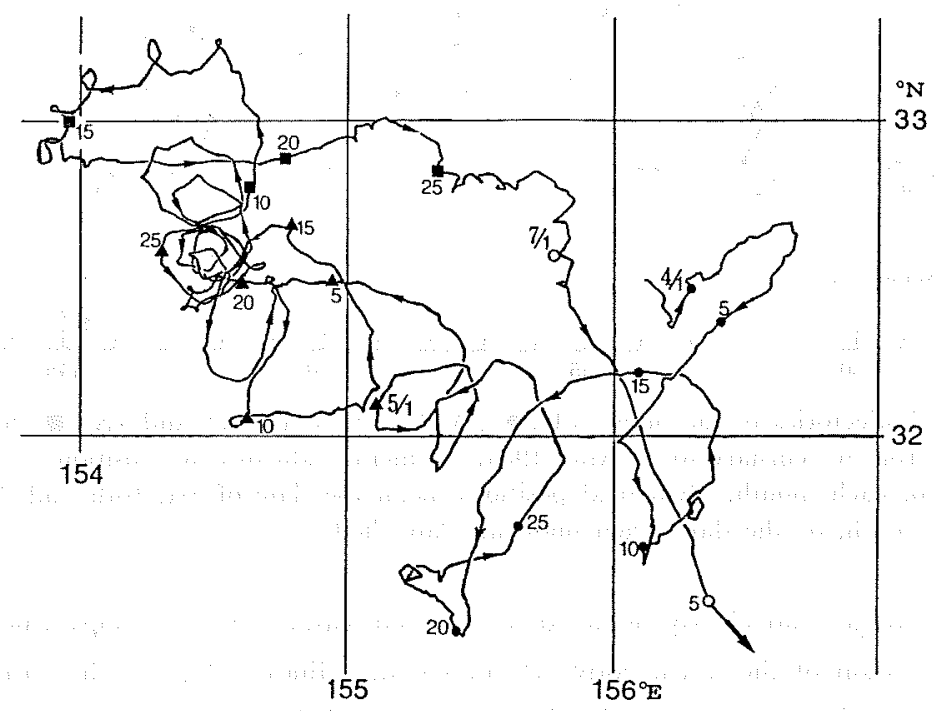

Figure 14 Trajectory of the buoy I in the period from 30 March to 5 July 1980. Numeral

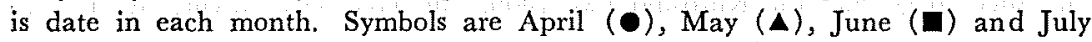
(O), respectively.

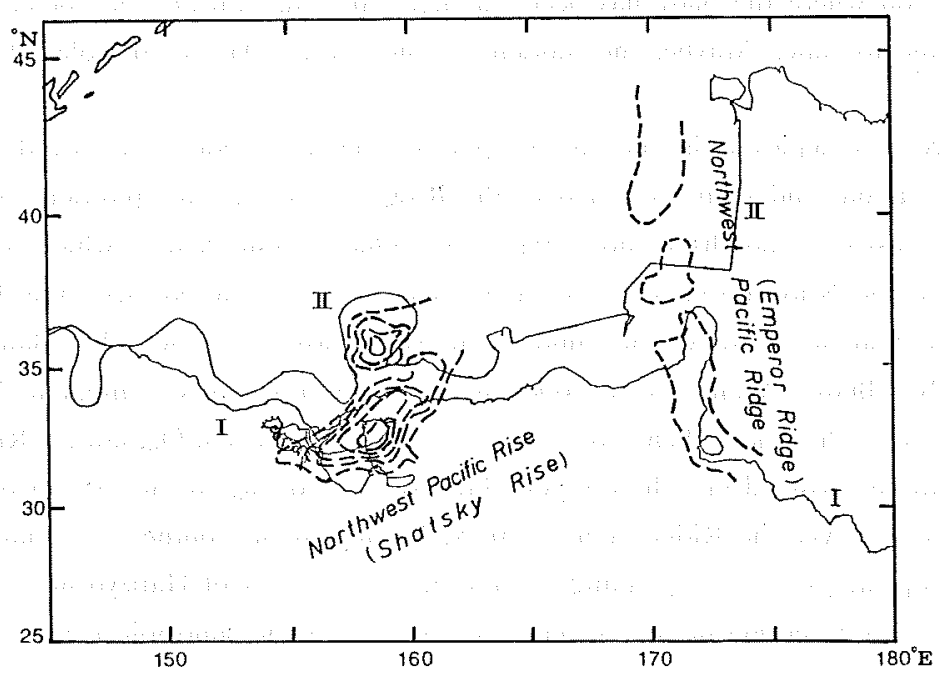

Figure 15 Trajectories (solid lines) of the buoys I and II, and rough sketch of depth contours (dashed lines). In adjacent to Shatsky Rise, contour is drawn at every $500 \mathrm{~m}$ from $4500 \mathrm{~m}$ depth, and $5000 \mathrm{~m}$ contour is drawn near Emperor Ridge. 
A few interesting facts are revealed by the superimposing of bottom topography on the buoy tracks (Figure 15). The region where buoy I had been staying corresponds to the Northwest Pacific Rise (Shatsky Rise). For buoy II, the meandered motion whose center is at $36^{\circ} \mathrm{N}, 158^{\circ} \mathrm{E}$ tends to be along the contour of the sea mount; which is a part of the Shatsky Rise and rises to the height of $3000 \mathrm{~m}$ from the surrounding sea floor with depth of more than $6000 \mathrm{~m}$. Further, the Northwest Pacific Ridge (Emperor Ridge) stands in the place where two buoys flowed separately at $172^{\circ} \mathrm{E}$ in the opposite direction.

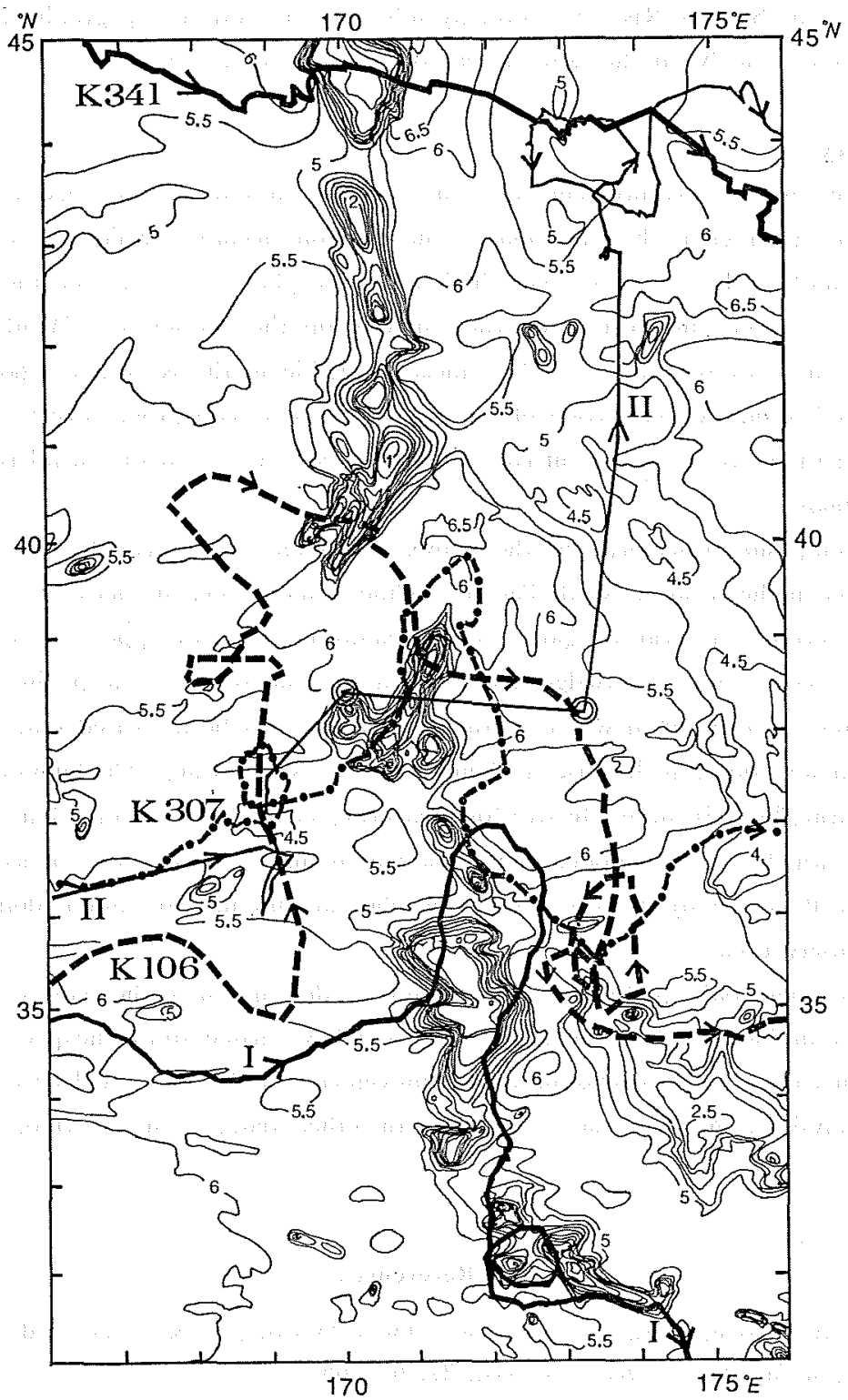

Figure 16 Trajectories of the buoys (I and II) and Kirwan's drifters which are denoted by prefix " $\mathrm{K}$ ". Numeral shows depth in $\mathrm{km}$. The buoy II did not send the messages during the period from 23 June to 26 July 1980 (between two symbols (O)). 
Detailed picture near the Emperor Ridge is given in Figure 16. In this figure, the trajectories of three drifters which were deployed by A. D. Kirwan and reached to the Ridge, are also shown (Nishida, 1978a, b). For buoy II, it is not known how tracks was made when the buoy crossed over the Ridge, because it did not send messages while crossing the Ridge. The drifting pattern of buoy $\mathrm{I}$ and $\mathrm{K} 307$ is quite similar each other. Including the K106 drifter, three buoys show a common tendency that buoy turns to the north when it approach to the Ridge and then turn back to the south, making clockwise trajectory. Furthermore, they often show a tendency to flow along the contour of sea mounts. Hence, looking over the behavior of drifting buoys near the Emperor Ridge and the Shatsky Rise, it is strongly felt that the bottom topography has great effect on the buoys' motions, namely on the flow pattern of near-surface current.

\section{Summary}

Surface current measurement with the satellite-tracked drifting buoys has been carried out in the Kuroshio region. Examination of the position accuracy which is important for buoy experiment, shows that the accuracy is very high when the platform is fixed on the earth, and also is satisfactory for measuring surface current when drifting on the sea surface. Wind effect on drifting speed/course of the buoy is estimated to be almost negligible in the Kuroshio region where a typical current speed is 1 knot. A comparison of the buoy trajectory with progressive vector of geostrophic wind shows that there are no significant correlation between them, and that wind is ineffective on the motion of the buoy.

The composite trajectories of the buoys, in a large scale, gives the classical picture of the ocean circulation in the western North Pacific. While in mesoscale, the buoys detected eddies, meanders or looped currents in various regions. Those mesoscale features appeared to be rather curious and interesting, because our knowledge about ocean current is poor except in very limited area like the Kuroshio south of Japan where routine observation has been carried out. In particular, the cold eddy which was found in the east of Okinawa Island is surprising. The buoy-tracking experiment proved that drifting buoy is quite effective for measuring surface current for a long time, especially in the region over which the conventional ship observation might not extend. Hence, it is hoped that drifting buoys will be deployed more widely for obtaining useful information, along with more dense hydrographic observation.

In this report, only qualitative and preliminary description of the buoy trajectories is made, although several problems which should be discussed have arisen from unexpected behavior of the buoys. The rather quantitative discussion for the movements of the buoys will be made later, through the detailed analysis of the buoy data together with other data, such as wind, XBTs and serial observation.

\section{References}

Cheney, R. E., Richardson, P. L., Nagasaka, K. 1980 : Tracking a Kuroshio cold eddy with a freedrifting surface buoy. Deep-Sea Res., 27, 641-654.

Cresswell, G. R., Golding, T. J., Boland, F. M. 1978 : A buoy and ship examination of the subtropical convergence south of western Australia. J. Phys. Oceanogr., 8, 315-320.

Kirwan, A. D. Jr., McNally, G. J., Chang, M.-S., Molinari, R. 1975 : The effect of wind and surface 
Kirwan, A. D. Jr., McNally, G. J., Coehlo, J. 1976 : Gulf Stream kinematics inferred from a satellitecurrents on drifters. J. Phys. Oceanogr., 5, 361-368.

tracked drifter. J. Phys. Oceanogr., 6, 750-755.

Kirwan, A. D. Jr., McNally, G. J., Reyna, E., Merrell, W. J. Jr. 1978 : The near-surface circulation of the eastern North Pacific. I. Phys. Oceanogr., 8, 937-945.

Nishida, H. 1978a : Current observation with the satellite-tracked drifters. The Kuroshio Meander and Cold Water Mass, 1978, 81-90 (in Japanese).

Nishida, H. 1978b : Tracking of drifting buoys by the satellite and its application for current measurement. Mar. Sci. Monthly, 7, 593-603 (in Japanese).

Nishida, H. 1982 : Description of the Kuroshio meander in 1975-1980. Rep. Hydrogr. Res., No. 17, 181-207.

Richardson, P. L., Cheney, R. E., Mantini, L. A. 1977 : Tracking a Gulf Stream ring with a free drifting surface buoy. J. Phys. Oceanogr.,7, 580-590.

Richardson, P. L. 1980 : Gulf Stream ring trajectories. J. Phys. Oceanogr., 10, 90-104.

Reed, R. K. 1980 : Direct measurement of recirculation in the Alaskan Stream. J. Phys. Oceanogr., 10, $976-978$. 